\title{
Mechanical properties of cement-treated soil improved using urea
}

\author{
Kazuhiro Kaneda ${ }^{\text {i) }}$, Tomohiro Tanikawa ${ }^{\text {ii) }}$,Yuichi Koumura ${ }^{\text {i) }}$ and Toshiro Hata ${ }^{\text {iii }}$ \\ i) Chief Researcher, Takenaka Research \& Development Institute, 1-5-1 Ohtsuka, Inzai, Chiba, 270-1395, Japan. \\ ii) Researcher, Takenaka Research \& Development Institute, 1-5-1 Ohtsuka, Inzai, Chiba, 270-1395, Japan. \\ iii) Associate Professor, Toyama Prefectural University, 5180 Kurokawa, Imizu, Toyama, 939-0398, Japan.
}

\begin{abstract}
In general, a high strength soil improvement can be achieved by increasing cement amount or decreeing water-cement ratio(w/c). However, because cement milk of low water-cement ratio is viscous, when the cement milk with w/c under $60 \%$ is used in the soil improvement, the pressure feed of cement milk cannot be performed. To solve this problem, fluidizers are used with cement milk. On the other hand, in the field of concrete it is known that mobility will increase by mixing urea with concrete. In this research, the attention is paid to fluid improvement mixing urea with soil -cement water. Laboratory experiments and field experiments were conducted to clarify the effect of using urea on the improved mixed soil by discussing its strength variation and mobility.
\end{abstract}

Keywords: soil improvement, urea, variation

\section{INTRODUCTION}

Grid-form deep mixing walls (Suzuki et al. 1996 and Taya et al. 2008) are a liquefaction countermeasure in which cement milk is injected into the soil in order to strengthen it. The cement-treated soil that results from such operation must sufficiently be strong and the amount of sludge must be low enough to provide effective design flexibility and keep costs at acceptable levels. In general, to increase the strength of cement-treated soil, the amount of cement is increased or the water-cement ratio (W/C) is lowered. For example, when the amount of cement per unit volume is increased and the volume of sludge is reduced, it is necessary to lower the water-cement ratio. However, cement milk with low W/C is highly viscous and pumping it becomes difficult when $\mathrm{W} / \mathrm{C}$ is under $60 \%$. One solution to this is to lower the W/C and add a fluidizing agent that keeps the viscosity low.

In the concrete field, research on preventing concrete cracking with urea as an admixture has been carried out. Urea dissolves easily in water. Adding urea reduces the unit quantity of water needed and increases its fluidity. This research, investigates, through laboratory and field tests, whether high-strength cement-treated soil can be made using urea-treated cement, as influenced by pump pressure feed and stirring. Field tests were also performed to investigate the construction workability of urea cement-treated soil and its strength variation with depth.

\section{LABORATORY TEST}

Experiments were conducted on the mobility of cement milk and soil cement. Cement milk is defined here as a mixture of water and cement or water, cement, and urea. Soil cement is defined as a mixture of cement milk and soil. Table 1 shows the material properties used in this experiment. The soil was beach sand collected in a reclaimed land region in Futtsu-shi, Chiba, Japan. The soil was mixed using a mixer to make it as uniform as possible. The natural soil water content is 25.8\%. Portland blast-furnace slag cement B and agricultural urea were used.

Table 1. Material properties.

\begin{tabular}{|l|l|}
\hline Cement & $\begin{array}{l}\text { Portland blast-furnace slag cement B } \\
\text { Density: } 3.04 \mathrm{~g} / \mathrm{cm}^{3}\end{array}$ \\
\hline Urea & $\begin{array}{l}\text { Agricultural urea } \\
\text { Density: } 1.32 \mathrm{~g} / \mathrm{cm}^{3}\end{array}$ \\
\hline Soil & $\begin{array}{l}\text { Futtsu sand } \\
\text { Wet density: } 1.89-17.2 \mathrm{~g} / \mathrm{cm}^{3} \\
\\
\text { Natural water content: } 22.4-32.2 \%\end{array}$ \\
\hline
\end{tabular}

\section{EXPERIMENTAL RESULTS AND CONSIDERATIONS}

To check the mobility of the cement milk, P-type funnel experiments (JSCE-F 521-1999) were performed by changing the mass ratios of water, cement, and urea (W/C $=45-60 \%, \mathrm{U} / \mathrm{C}=0-20 \%$ ). The cement milk was made by adding water or urea water (urea dissolved in water) into cement and mixing them for 3 minutes. 30 
minutes after mixing, the P-funnel flowing time was measured. The water temperature dropped due to endothermic dissolution. Therefore, the experiments were performed after the urea water reached a stable temperature. Table 2 lists the combinations of ingredients added to $1 \mathrm{~kg}$ of soil. In cases 1 to 3 the urea concentration was varied at a constant W/C of $60 \%$. In cases 4 to 6 , both W/C and urea concentration were varied. When the total volume of Case 1 is assumed as a unit volume, the total volume of the other cases relative to the one of Case 1 ranged from 0.99 to 1.02. This indicates that the volume of sludge used in actual construction is almost the same whether or not urea is added. The mobility of the soil cement using a mortar flow test as per JIS R 5201 was checked: measurements were taken just after flow cone had been extracted and up and fall down movements were carried out 15 times. Vane shear testing was also performed. After 4 weeks of curing, three unconfined compression tests were performed for each case.

Table 2. Cement milk composition.

\begin{tabular}{|c|c|c|c|c|c|c|c|c|}
\hline & Soil & Cement & Water & Urea & $\begin{array}{l}\text { Water-cement } \\
\text { ratio }\end{array}$ & $\begin{array}{l}\text { Urea-cement } \\
\text { ratio }\end{array}$ & $\begin{array}{l}\text { Water urea- } \\
\text { cement ratio }\end{array}$ & Volume \\
\hline & $S$ & C & W & $\mathrm{U}$ & W/C & $\mathrm{U} / \mathrm{C}$ & $(\mathrm{W}+\mathrm{U}) / \mathrm{C}$ & $\mathrm{V}$ \\
\hline Unit & $\mathrm{g}$ & $\mathrm{g}$ & $\mathrm{g}$ & $\mathrm{g}$ & $\%$ & $\%$ & $\%$ & $\mathrm{~cm} 3$ \\
\hline Case 1 & 1000 & 167 & 100 & 0 & 60.0 & 0.0 & 260.0 & 651 \\
\hline Case 2 & 1000 & 167 & 100 & 9 & 60.0 & 5.2 & 65.2 & 658 \\
\hline Case 3 & 1000 & 167 & 100 & 17 & 60.0 & 10.3 & 70.3 & 664 \\
\hline Case 4 & 1000 & 167 & 83 & 17 & 50.0 & 10.3 & 60.3 & 648 \\
\hline Case 5 & 1000 & 167 & 75 & 34 & 45.0 & 20.7 & 65.7 & 652 \\
\hline \begin{tabular}{|l|} 
Case 6 \\
\end{tabular} & 1000 & 167 & 75 & 52 & 45.0 & 31.0 & 76.0 & 665 \\
\hline
\end{tabular}

Figures 1 and 2 show the relationship between the P-funnel flowing time and the ratios of urea and urea water to cement, respectively. In cases where the $\mathrm{P}$ funnel flowing time is under $14 \mathrm{~s}$, wall construction is feasible (Tamaki et al. 2013). The flow time is $10.5 \mathrm{~s}$ without urea at a W/C of $60 \%$, which corresponds to the cement milk with the smallest amount of water used in normal construction. For W/C of 50\% and $45 \%$, the flow times were $17.5 \mathrm{~s}$ and $54.3 \mathrm{~s}$, respectively. When the urea concentration was increased, the flow time dropped for both $50 \%$ and $45 \%$ W/C cases. The viscosity of the cement milk improved the flow time to $14 \mathrm{~s}$ when $10-15 \%$ urea admixtures were used. These values are feasible values in construction. The tests showed that flow times slowed down after 30 minutes for low W/C or small urea concentration. Figure2 shows the approximate curves of flow times just after blending and after 30 minutes of mixing. It indicates that in order to have flowing times below $14 \mathrm{~s}$, $(\mathrm{W}+\mathrm{U}) / \mathrm{C}$ must be more than $60 \%$. Figure 3 shows the relationship between flowing time after 30 minutes and the ratio of urea water to cement. The flowing time for a W/C of $45 \%$ is larger than at $50 \%$. In both cases where $(\mathrm{W}+\mathrm{U}) / \mathrm{C}$ is $60 \%$, the flow time is small. Therefore, having $(\mathrm{W}+\mathrm{U}) / \mathrm{C}$ above $60 \%$ is advantageous for construction. Figures 4 and 5 show the vane shear test results and the values from the mortar flow tests, respectively. When the urea concentration increases, the value of mortar flow test increases and the vane shear strength drops. This indicates that the fluidity of cement milk improves with the use of urea. In cases 4,5 , and 6 , which have low W/C values, the fluidity improves similarly to case 1 .

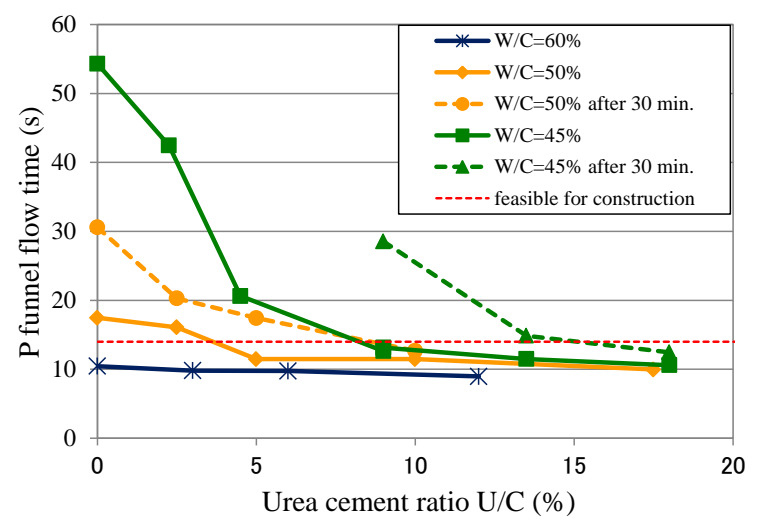

Fig. 1. Relationship between $P$ funnel flowing time and urea-cement ratio.

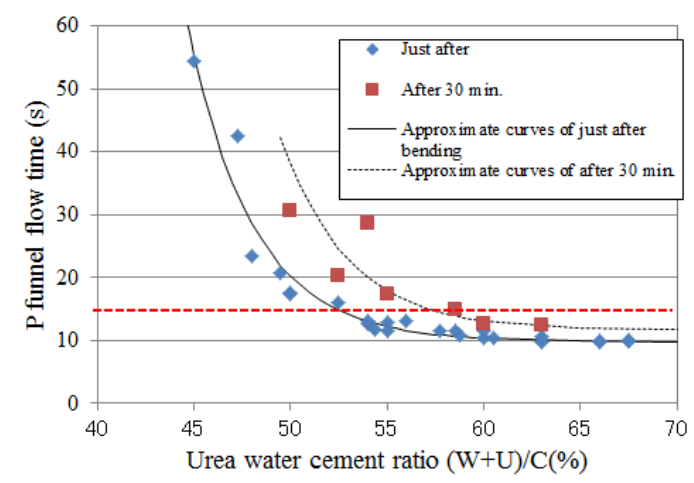

Fig. 2. Relationship between $P$ funnel flow time and urea water-cement ratio.

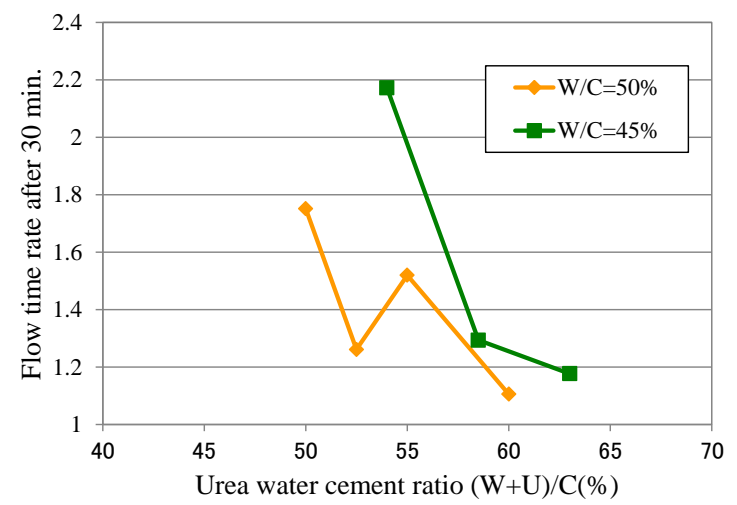

Fig. 3. Relationship between $P$ funnel flow time rate after 30 minutes and urea water-cement ratio.

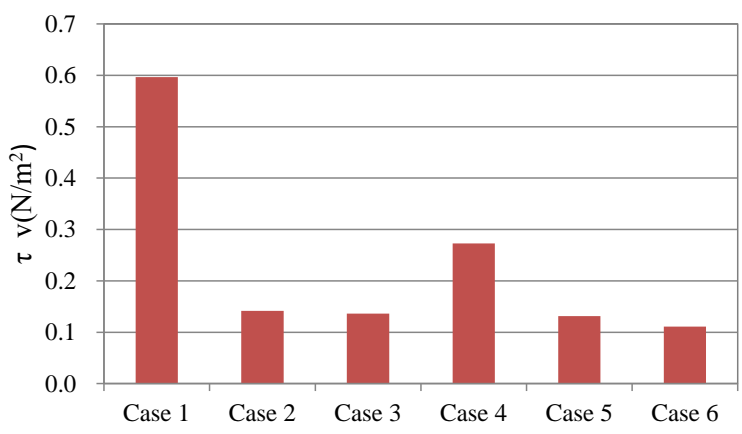

Fig. 4. Vane shear test strength results. 


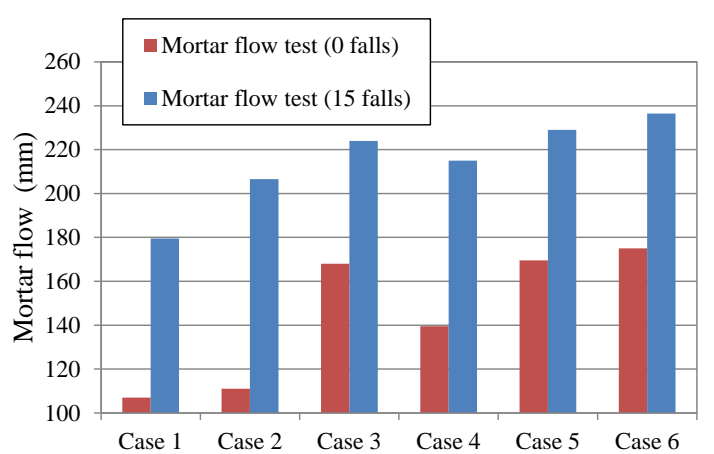

Fig. 5. Mortar flow test results (0 fall, 15 falls).

Figure 6 shows the results of unconfined compression tests after 4 weeks of curing. It indicates the average values for three samples for each case. The strengths of cases 1 to 3 are almost the same despite the various urea concentrations. This shows that there is little effect on strength when the urea concentration is under 10\%. Although in Case $4(\mathrm{~W} / \mathrm{C}=50 \%)$, there is the same amount of cement as in cases 1 to 3 (W/C $60 \%$ ), the samples were 1.2 times stronger because there is less water. Thus Case 4's cement-treated soil has high strength but uses the same volume of sludge as the other cases. Cases 5 and 6, however, in spite of their high cement content milk, are weaker than Case 4. This is likely because the urea delays cement's hydration reaction. In cases 5 and 6 the cement-treated soil had concentrations of urea greater than $20 \%$. This could have retarded the hydration and slowed the rate at which its strength increased.

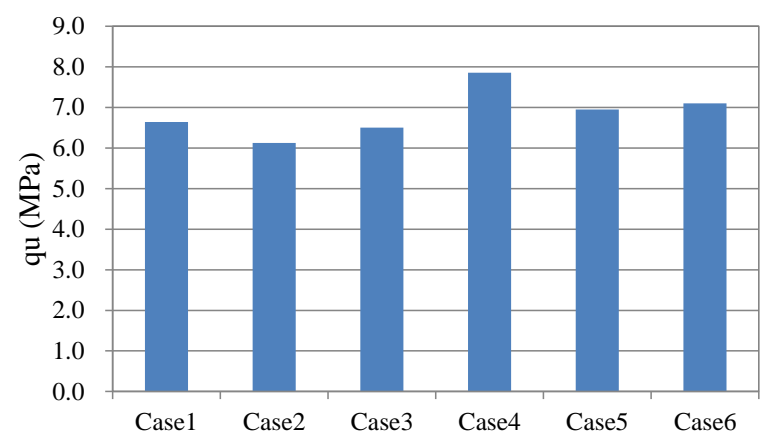

Fig. 6. Unconfined compressive strength.

\section{FIELD TESTS}

Field tests were performed in Futtsu, Chiba, Japan to investigate the effect that improving cement milk fluidity has on the strength of soil cement. Figure 7 shows the soil profile. The embankment is located from the surface to $4 \mathrm{~m}$ deep (GL-4m). Below this level there is fine sandy soil. The soil was improved from GL-4m to GL-9m. DCM-L, Ф 1000mmx2 machine was used and deep mixing with slurry was performed. The 2-axis mixing machine is available along a 3 -fulcrum pile leader. The cement slurry spouted from the top of each rotary shaft and while the cement slurry was poured and mixed into the soil, the shaft dug to the planned depth under its own weight and the mixing machine rotation. 2-axis soil improvement columns of regular strength using the normal chemical reaction of cement was constructed. In this experiment, different amounts of urea with the cement slurry were mixed. Table 3 shows the experimental cases. U/C changes but the amounts of cement $\left(330 \mathrm{~kg} / \mathrm{m}^{3}\right)$ and water $(\mathrm{W} / \mathrm{C}=60 \%)$ are held constant. Figure 8 shows the construction layout. The space between cases was $1 \mathrm{~m}$. The mixing rotation rate was $18.5 \mathrm{rpm}$ at penetration and $37.0 \mathrm{rpm}$ at drawing. The unconfined compression tests at 4 weeks of curing used samples collected by core boring at three points (see figure 9) 3 weeks after construction.

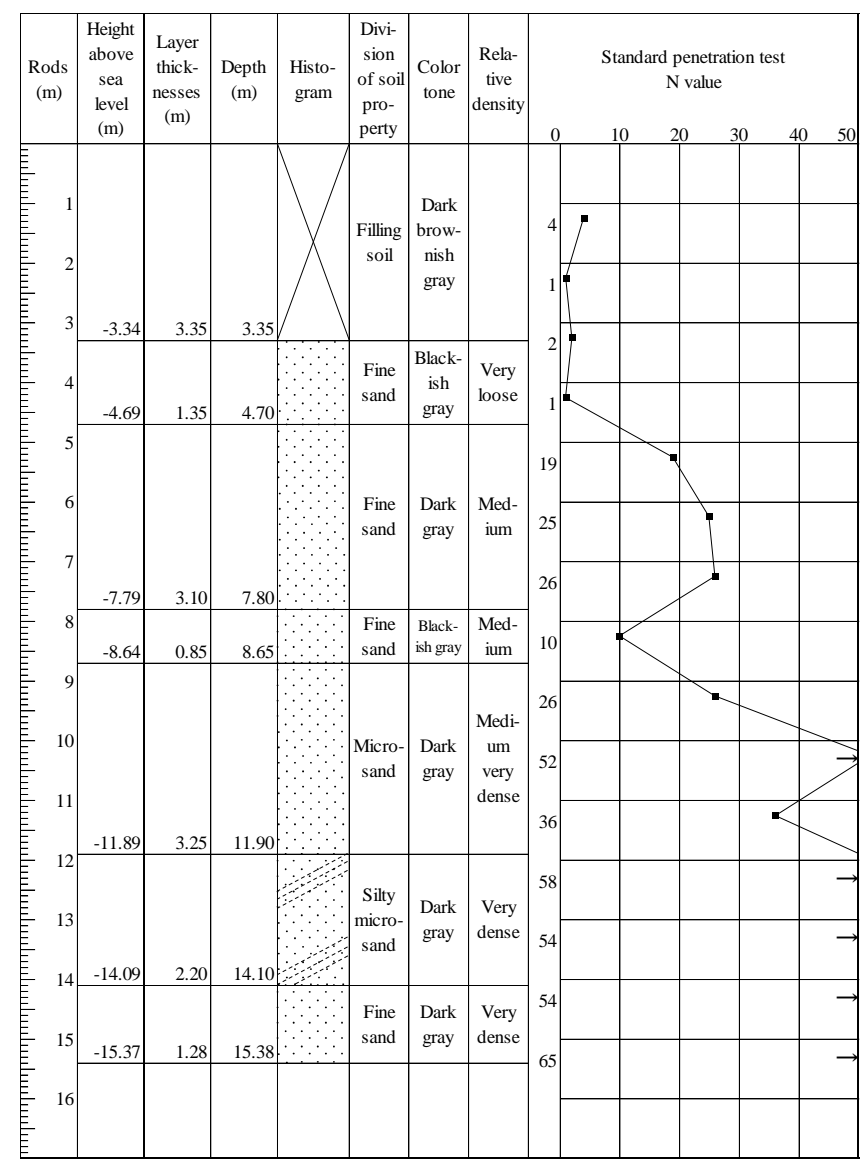

Fig. 7. Soil profile.

Table 3. Experimental cases.

\begin{tabular}{|c|c|c|c|}
\hline & Cement $\left(\mathrm{kg} / \mathrm{m}^{3}\right)$ & $\mathrm{W} / \mathrm{C}(\%)$ & $\mathrm{U} / \mathrm{C}(\%)$ \\
\hline Case 1 & 330 & 60 & 0 \\
\hline Case 2 & 330 & 60 & 5 \\
\hline Case 3 & 330 & 60 & 10 \\
\hline
\end{tabular}




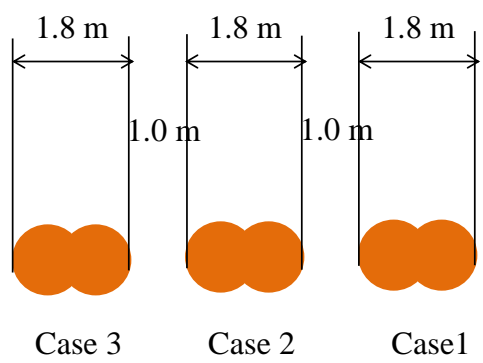

Fig. 8. Construction layout.

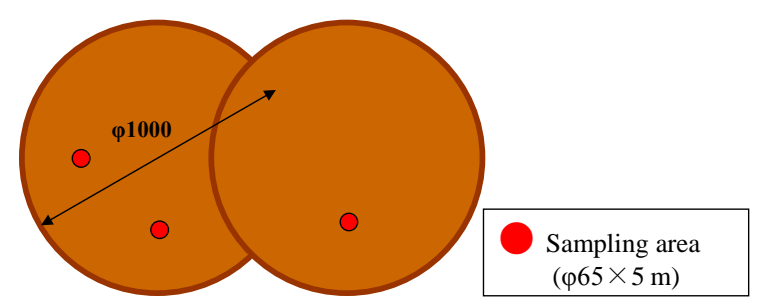

Fig. 9. Core boring locations.

\section{FIELD TEST RESULTS}

Figure 10 shows the relationship between the unconfined compressive strength, density, and depth. The strength increases from the top to GL-6m. Below GL-6m, no increase in strength is evident. This is because the cement milk was pushed out during construction around the ground surface. The strength is so large that the density is also large. Table 4 shows the averages, standard deviations and coefficients of variation of unconfined compressive strength below GL-6m. The coefficient of variation of the urea sample is clearly smaller than of the other samples. It can be seen that a more homogeneous sample was made using urea.
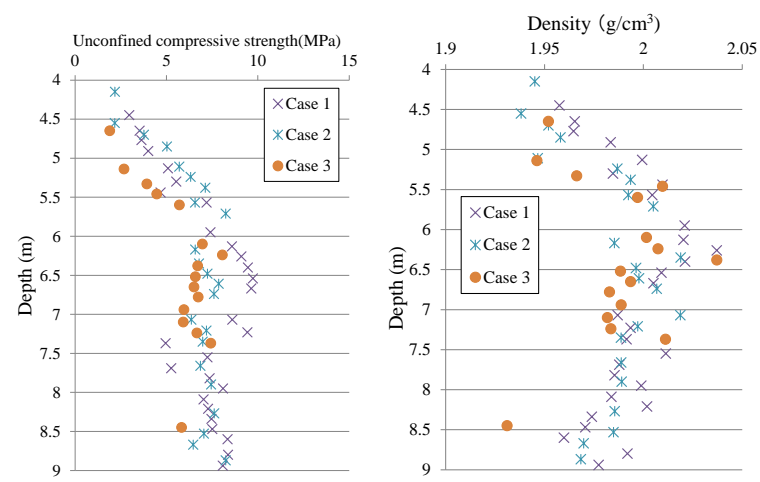

Fig. 10. Unconfined compressive strength and density versus depth.

Table 4. Results of experiments

\begin{tabular}{|c|c|c|c|}
\hline & Averages & $\begin{array}{c}\text { Standard } \\
\text { deviations }\end{array}$ & $\begin{array}{c}\text { coefficients of } \\
\text { variation }\end{array}$ \\
\hline Case 1 & 7.98 & 1.29 & 16.21 \\
\hline Case 2 & 7.16 & 0.53 & 7.35 \\
\hline Case 3 & 6.67 & 0.63 & 9.49 \\
\hline
\end{tabular}

\section{CONCLUSION}

Laboratory tests were performed on cement-treated soils including urea as an admixture. When the urea concentration was high with a constant W/C, the fluidity of the cement milk was improved along with the soil cement. When W/C was lower but fluidity was maintained, high-strength cement-treated soils were produced using less sludge. Construction was feasible when W/C was between $45 \%$ and $60 \%$, provided that $(\mathrm{W}+\mathrm{U}) / \mathrm{C}$ remains above $60 \%$. When $(\mathrm{W}+\mathrm{U}) / \mathrm{C}$ was below $10 \%$, the hydration reaction in the cement was not delayed to an unsatisfactory extent. With an appropriate urea concentration, high-strength cement-treated soils can be constructed while reducing the amount of construction sludge required.

Unconfined compression tests were also performed at 4-week curing time using samples collected at three points in each column by core boring 3 weeks after construction. The coefficient of variation of the sample containing urea was smaller than those of the other samples. It can be seen that a more homogeneous sample was made using urea to improve fluidity.

\section{ACKNOWLEDGEMENTS}

The authors are grateful to the Center for Revitalization Promotion of the Japan Science and Technology Agency for providing funds. The authors also wish to thank Dr. Taka-aki Mizutani of the Port and Airport Research Institute for his especially helpful comments.

\section{REFERENCES}

1) Kawai, T. and Sakata, K. (2007): Some properties of concrete using urea, Proceedings of Japan Concrete Institute, Vol. 29, No. 1.

2) Suzuki, Y., Saito, S., Onimaru, S., Kimura, T., Uchida, A. and Okumura, R. (1996): Grid-shaped Stabilized Ground Improved by Deep Cement Mixing Method against Liquefaction for a Building Foundation, Tsuchi-to-Kiso, Vol. 44, No. 3, 46-48, Japanese Geotechnical Society.

3) Taya, Y., Uchida, A., Yoshizawa, M., Onimaru, S., Yamashita, K. and Tsukuni, S. (2008): Simple method for determining lattice intervals in grid-form ground improvement, Japanese Geotechnical Journal, Vol. 3, No. 3, 203-212.

4) Tazaki, S., Kinoshita, M., Saito, K., Aoki, M., Kono, T., Ueda, M., Kokaki, H. and Yonezawa, T. (2013): Reduction of water-cement ratio of cement milk using high-volume blast furnace slag cement, Summaries of Technical Papers of Annual Meeting, Architectural Institute of Japan. 